\title{
Sildenafil citrate therapy in absent end diastolic flow in umbilical artery in an early onset fetal growth restriction (FGR) fetus
}

\author{
Rana A. Choudhary ${ }^{1 *}$, Khyati Patrawala ${ }^{2}$, Kavita Desai ${ }^{3}$, Kedar Ganla ${ }^{2}$
}

\begin{abstract}
${ }^{1}$ Department of Reproductive Medicine, ${ }^{2}$ Department of Obstetrics and Gynecology, Ankoor Fertility Clinic, Mumbai, Maharashtra, India

${ }^{3}$ Consultant Sonologist, Dadar Imaging and Diagnostic Centre, Mumbai, Maharashtra, India
\end{abstract}

Received: 18 September 2018

Accepted: 22 October 2018

\author{
*Correspondence: \\ Dr. Rana A. Choudhary, \\ E-mail: dr.ranakhan@gmail.com
}

Copyright: (c) the author(s), publisher and licensee Medip Academy. This is an open-access article distributed under the terms of the Creative Commons Attribution Non-Commercial License, which permits unrestricted non-commercial use, distribution, and reproduction in any medium, provided the original work is properly cited.

\begin{abstract}
Fetal growth restriction (FGR), a pregnancy complication still poses as a challenge for obstetricians worldwide. This is because of its association with severe morbidity and mortality outcomes. Obstetrical management becomes a dilemma in determining the optimal time of delivery and weighing the risks of prematurity against the risks of a potentially hostile intrauterine environment. There may be placental insufficiency characterized by insufficient blood flow in the umbilical artery. This is termed as abnormal umbilical artery flow with absent or reversed end diastolic flow on Doppler USG. Worsening of this condition demands an earlier delivery of the fetus. Authors report a case of structurally normal foetus showing severe early onset FGR with absent end diastolic flow in umbilical artery on Doppler, which was managed using vaginal Sildenafil citrate. Sildenafil citrate led to improvement in uterine artery and umbilical artery Doppler parameters; thereby improving the utero-placental blood flow with a favorable fetal outcome at delivery. The gestation was prolonged by 51 days. Thus, Sildenafil citrate can be used as promising agent in early onset FGR in selected cases.
\end{abstract}

Keywords: Absent end diastolic flow, Fetal growth restriction, Intra uterine growth restriction, Sildenafil citrate, Umbilical artery

\section{INTRODUCTION}

The incidence of intrauterine fetal growth restriction (IUGR/ FGR) is quite high in Indian population. ${ }^{1} \mathrm{~A}$ definitive consensus on this clinical condition has yet not been established inspite of the currently available management options. Some pregnancies with fetal growth restriction (FGR) have elevated peripheral maternal vascular resistance in uterine arteries and hence poor perinatal outcome. Placental insufficiency might result in further deterioration of fetal growth and lowbirth weight during gestation. Abnormal umbilical artery flow with absent or reversed end-diastolic velocity (AREDV) on Doppler USG during pregnancy is an indication of placental insufficiency. When AREDV occurs, a close follow-up or expeditious delivery should be contemplated. These premature neonates are at an increased risk for intraventricular hemorrhage, bronchopulmonary dysplasia, necrotizing enterocolitis, respiratory distress syndrome or long-term neuro development impairment. Hence pregnancy prolongation is of significant value in such cases. ${ }^{2}$ Also according to classical definition of IUGR, increase in fetal birth weight is associated with improved pregnancy outcomes. ${ }^{3}$ Sildenafil was initially studied for use in hypertension (high blood pressure) and angina pectoris (a symptom of ischaemic heart disease). ${ }^{4}$ Studies have shown that Sildenafil citrate increases uterine blood flow and potentiates estrogen-induced vasodilatation. ${ }^{5}$ Authors present a case of early onset fetal growth 
restriction (FGR) where administration of vaginal Sildenafil citrate could normalize the uteroplacental insufficiency with a favorable fetal outcome.

\section{CASE REPORT}

A 33 years old lady had conceived with in vitro fertilization in view of poor ovarian reserve. Her antenatal course was uneventful, but her 22 weeks scan (foetal 2D echo) showed increased resistance in left uterine artery. She was started on vasodilators like nitric oxide donor (L-arginine) $3 \mathrm{~g}$ daily. Four weeks later, there was clinical suspicion of intrauterine FGR and oligohydramnios, hence an early Doppler ultrasonography was done (Figure 1 and 2).

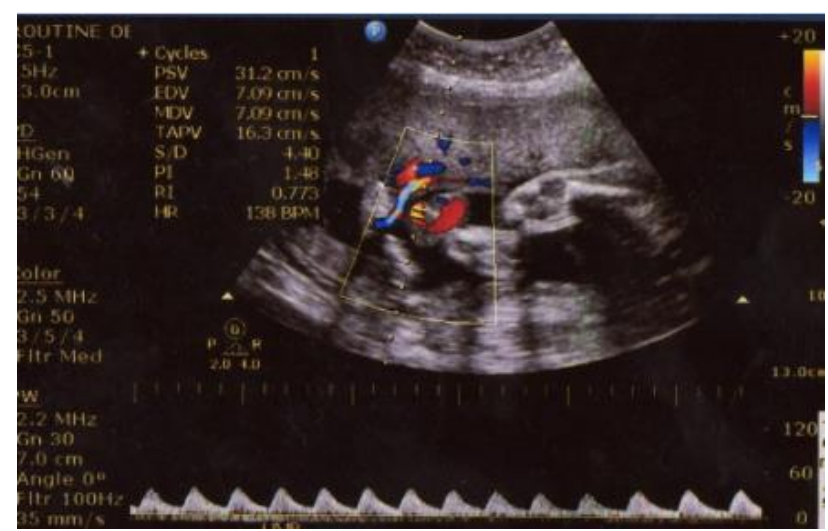

Figure 1: Doppler image of fetus at 26 weeks of gestation showing increased S/D ratio in right umbilical artery.

This sonography (Figure 1 and 2) showed an increased resistance in both umbilical arteries (S/D 4.4 and 3.8) with (PI 1.4, RI 0.7) and (PI 1.2, RI 0.7) suggestive of feto-placental insufficiency. There was also increased systolic by diastolic (S/D) ratio (3.4) in the left uterine artery (PI-1.5, RI-0.7) and normal in the right uterine artery (S/D 1.8, PI -0.8, RI-0.4). The foetus showed two weeks lag in growth with normal amniotic fluid index (AFI). The ductus venosus and foetal aorta revealed normal flow pattern on colour and spectral flow.

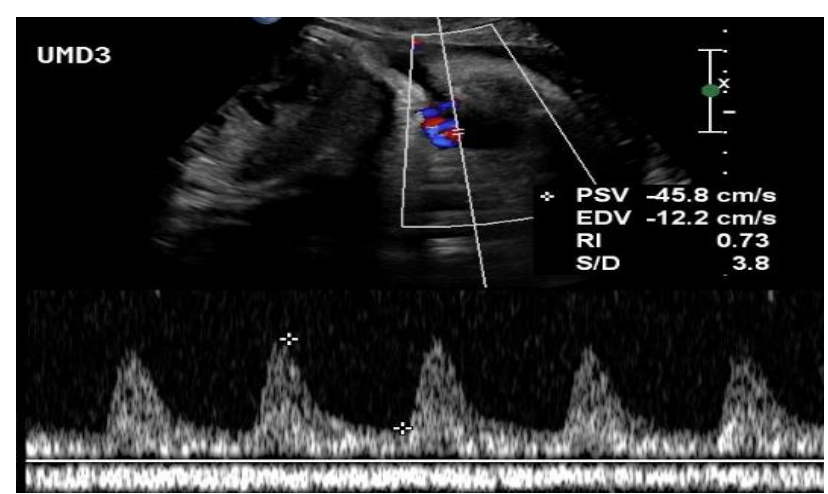

Figure 2: Doppler image fetus at 26 weeks of gestation showing increased S/D ratio in left umbilical artery.

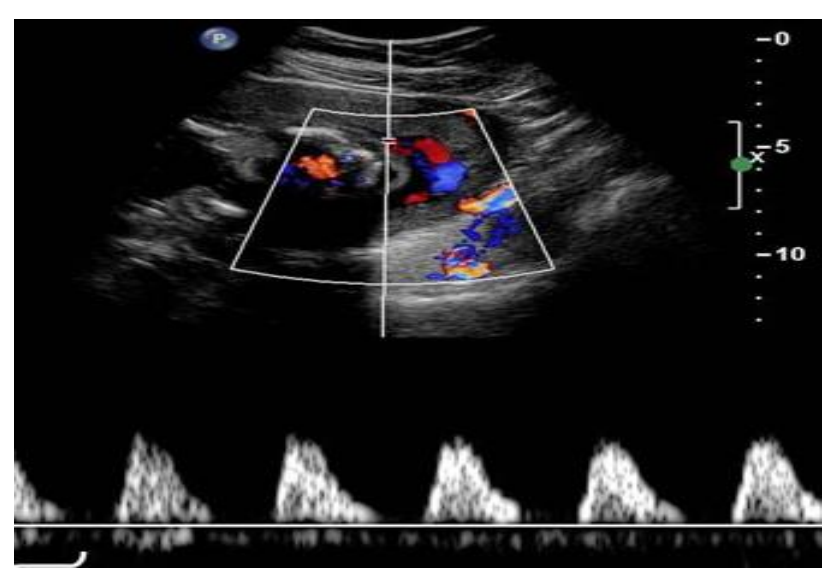

Figure 3: USG Doppler showing absent end diastolic flow (AEDF) in umbilical arteries at 30 weeks.

To reduce risk of foetal mortality and morbidity, the patient was kept on aspirin $75 \mathrm{mg}$ once daily along with other supportive measures like bed rest, increased protein diet, alamine infusion (once a week), hydration (minimum intake of 3-4 litres of fluid daily), and Larginine was continued.

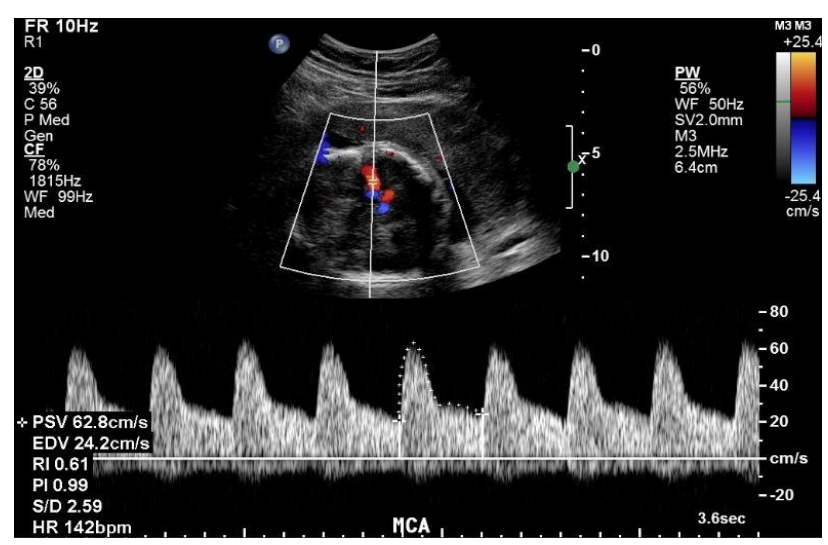

Figure 4: USG Doppler showing brain sparing effect in MCA at 30 weeks on Doppler.

Her Doppler ultrasonography was repeated after 2 weeks (28 weeks of gestation). Sonography revealed further worsening of the Doppler parameters with mild oligohydramnios (AFI-7). There was asymmetric IUGR with expected foetal weight (EFW) of $745 \pm 116 \mathrm{~g}$ and lag of 2 weeks. The S/D ratio was further increased in the umbilical arteries suggestive of deteriorating perfusion to the fetus. This sonography showed S/D ratio of 4.2 (PI 1.3, RI 0.7) in left umbilical artery and 4.6 (PI 1.4, RI 0.7 ) in the right umbilical artery. The left uterine artery S/D ratio was 3.5 (PI -1.3, RI-0.7) while it was 2.1 in the right uterine artery (PI-1.0, RI-0.5). However, the middle cerebral artery (MCA) circulation was still preserved.

In view of FGR and prematurity, injection betamethasone $12 \mathrm{mg}$ two doses was given 24 hours apart. The supportive measures were continued along with strict monitoring of foetal movements by daily foetal kick 
count (DFKC) for 2 weeks when a USG Doppler was repeated. This Doppler ultrasonography (30 weeks of gestation), showed absent diastolic flow in the umbilical arteries (Figure 3) with brain sparing effect (Figure 4). Foetal MCA systolic velocity $23 \mathrm{~cm} / \mathrm{s}$ and diastolic velocity $9.7 \mathrm{~cm} / \mathrm{s}$ with $\mathrm{S} / \mathrm{D}$ ratio of 2.59 (PI-0.99, RI0.61). The AFI was 6 and EFW $986 \pm 120 \mathrm{~g}$.

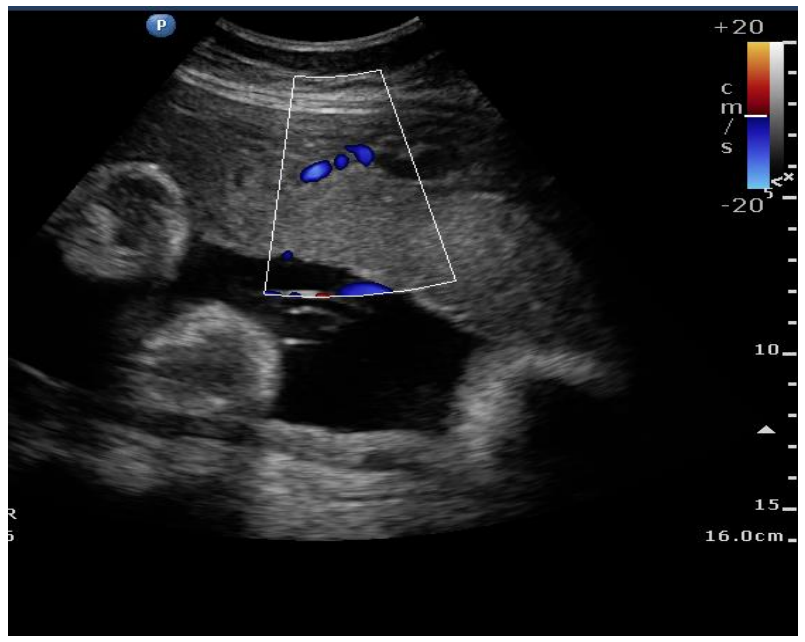

Figure 5: Doppler images of the myometrial placental junction before Sildenafil citrate treatment (30weeks).

The patient's blood pressure also started rising (BP$140 / 100 \mathrm{mmHg}$ ) around the same time and she was started on antihypertensive tablet Labetolol $100 \mathrm{mg}$ thrice daily orally. In view of the further deterioration in the blood flow to foetus as revealed by the worsening of Doppler indices, the couple was informed about prognosis of pregnancy. A decision to start vaginal Sildenafil citrate (Alivher®, Akumentis Healthcare Ltd.) $25 \mathrm{mg}$ thrice a day was taken after being explained about the experimental nature of the drug. Within a week of starting this drug, the patient noticed subjective improvement in fetal movements.

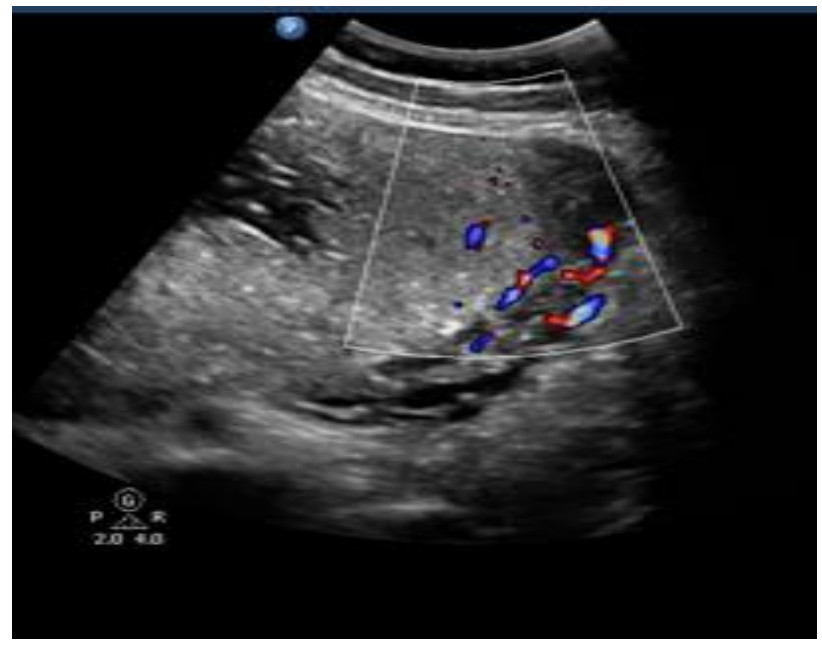

Figure 6: Doppler images of the myometrial placental junction after Sildenafil citrate treatment (32weeks).

Doppler along with biophysical profile (BPP) was repeated after one week (31 weeks). The Doppler showed that there was improvement in perfusion and the S/D ratio in uterine arteries reduced to 1.9 and 3.3 in the right and left uterine artery respectively. The foetal MCA systolic velocity $24 \mathrm{~cm} / \mathrm{s}$ and diastolic velocity $6.4 \mathrm{~cm} / \mathrm{s}$ with S/D ratio of 2.7 (PI-1.2, RI-0.7). This Doppler too showed absent diastolic flow in the umbilical arteries with brain sparing effect with an AFI of 7 and EFW $1150 \pm 130 \mathrm{~g}$. After 2 weeks of Sildenafil citrate treatment, at 32 weeks' gestation Doppler of myometrial placental junction showed improvement in flow pattern (Figure 5 and 6).

Table 1: Progress of pregnancy-Doppler changes during the gestation starting from 22 weeks till delivery.

\begin{tabular}{|c|c|c|c|c|c|c|c|c|c|c|}
\hline \multirow{2}{*}{$\begin{array}{l}\text { Dating } \\
\text { scan } \\
\text { (week) }\end{array}$} & \multirow{2}{*}{$\begin{array}{l}\text { GA by } \\
\text { current } \\
\text { USG }\end{array}$} & \multicolumn{2}{|c|}{$\begin{array}{l}\text { Umbilical artery } \\
\text { Doppler-PI }\end{array}$} & \multicolumn{2}{|c|}{$\begin{array}{l}\text { Uterine } \\
\text { artery S/D }\end{array}$} & \multirow{2}{*}{$\begin{array}{l}\text { BP } \\
(\mathrm{mmHg})\end{array}$} & \multirow[t]{2}{*}{ AFI } & \multirow[t]{2}{*}{ EBW (g) } & \multirow[t]{2}{*}{ MCA (S/D) } & \multirow[t]{2}{*}{ BPH } \\
\hline & & Right & Left & Right & Left & & & & & \\
\hline 22 & 21.6 & - & - & 1.4 & 2.4 & $110 / 80$ & - & $250 \pm 110$ & - & - \\
\hline 26 & 24 & 4.4 & 3.8 & 1.8 & 3.4 & $120 / 80$ & 12 & $570 \pm 110$ & 5.8 & $8 / 8$ \\
\hline 28 & 26.3 & 4.6 & 4.2 & 2.1 & 3.5 & $120 / 84$ & 7 & $745 \pm 116$ & 3.6 & $6 / 8$ \\
\hline $30 *$ & 28.2 & AEDF & AEDF & 2.2 & 3.5 & $140 / 100$ & 6 & $986 \pm 120$ & BSE 2.59 & $6 / 8$ \\
\hline $31 *$ & 29.3 & AEDF & AEDF & 1.9 & 3.3 & $140 / 90$ & 7 & $1150 \pm 130$ & BSE 2.7 & $8 / 8$ \\
\hline $32 *$ & 30.2 & AEDF & AEDF & 2.0 & 3.3 & $136 / 96$ & 8 & $1285 \pm 130$ & BSE 2.4 & $8 / 8$ \\
\hline $33^{*}$ & 31.1 & AEDF & AEDF & 1.9 & 3.2 & $130 / 90$ & 8 & $1415 \pm 120$ & BSE 2.6 & $8 / 8$ \\
\hline $34^{*}$ & 32.3 & AEDF & AEDF & 1.9 & 3.2 & $130 / 88$ & 8 & $1597 \pm 130$ & BSE 2.4 & $8 / 8$ \\
\hline $35^{*}$ & 33.2 & AEDF & AEDF & 1.9 & 3.2 & $130 / 90$ & 8 & $1751 \pm 140$ & BSE 2.4 & $8 / 8$ \\
\hline $36^{*}$ & 34 & AEDF & AEDF & 1.9 & 3.2 & $120 / 90$ & 8 & $1895 \pm 135$ & BSE 2.2 & $8 / 8$ \\
\hline $37 *$ & 35.1 & AEDF & AEDF & 2.0 & 3.3 & $140 / 90$ & 6 & $2050 \pm 130$ & BSE 2.2 & $6 / 8$ \\
\hline
\end{tabular}

AEDF-Absent end diastolic flow, BSE-Brain sparing effect, GA-Gestational age, S/D-Systolic: Diastolic ratio, LBW-Low birth weight, EFW-Estimated fetal weight, AFI-Amniotic fluid index. MCA-Middle cerebral artery, BPP-Biophysical profile, * - On Sildenafil citrate 
Thus, Sildenafil citrate can be agent behind the slight improvement in Doppler parameters and flow pattern. It was probably acting at these vessels at the placenta myometrial junction and hence there was prevention of further deterioration along with some improvement in the Doppler parameters and foetal growth. The Doppler ultrasound was repeated weekly as tabulated (Table 1).

Sildenafil citrate was stopped at 37 weeks and patient delivered by cesarean section at 37 weeks. A male baby of $2 \mathrm{kgs}$ with APGAR 8/10 at birth was born. Baby was admitted in NICU for observation and had an uneventful course. He was discharged on day 5. In this patient, authors managed to prolong pregnancy for almost 51 days, improve Doppler indices slightly even after absent end diastolic flow (AEDF) in both umbilical arteries along with brain sparing effect in the fetus. Neither the patient, nor the fetus showed any side effects to vaginal Sildenafil citrate. The baby was followed up for over 14 months and has normal milestones.

\section{DISCUSSION}

Adequate blood flow in uteroplacental vascular function is essential to achieve optimal fetal growth. Abnormal vasculature adaptation during embryogenesis and placentation, resulting in aberrant blood flow, has been implicated as a possible cause of fetal growth restriction (FGR). ${ }^{6}$ Absent end diastolic flow (AEDF) or Reversed end diastolic flow (REDF) result when either fetoplacental arteriolar pressure is equal to (AEDF) or exceeds (REDF) umbilical artery diastolic pressure. This increase in resistance to umbilical artery blood flow is determined by the existing degree of hypoxemic fetoplacental vasoconstriction (HFPV). Unresolving HFPV can cause umbilical arterial hypertension and right heart failure in the fetus or corplacental. ${ }^{7,8}$

A study by Wareing $M$ et al reported that in pregnancies with fetal growth restriction and without preeclampsia, there was a reversible increased myometrial arterial tone by phosphodiesterase inhibition in vitro. ${ }^{9}$ Sildenafil citrate is a phosphodiesterase (PDE5) inhibitor. ${ }^{9}$ PDE5 is responsible for the degradation of cGMP to guanosine monophosphate. ${ }^{10,11}$ Therefore, inhibiting PDE5 delays the breakdown of cGMP and hence increases vasodilation. ${ }^{10,11}$ A recent report suggested that Sildenafil citrate stimulates vasodilation in myometrial biopsies collected from IUGR pregnancies at the time of Cesarean section. ${ }^{9}$

Further animal studies have shown that PDE5 inhibition by sildenafil has shown to counter fetoplacental vasoconstriction induced by both 5-hydroxytryptamine and hypoxic conditions. ${ }^{7}$ Therefore, the alteration of fetal blood distribution by PDE5 inhibition would enhance fetal oxygenation and modulation of HFPV, while simultaneously improving fetal nutrition and hence improve FGR.
In present case, Sildenafil citrate was used in fetal growth restriction in an attempt to induce vasodilatation and improve uteroplacental perfusion resulting in improved Doppler indices. Sildenafil citrate vasodilates the vessels at the myometrio-placental junction in women with IUGR-complicated pregnancies. $^{12}$ Thus it showed improvement in amniotic fluid, as was also seen in a study by von Dadelszen $P$ et al. ${ }^{7,13}$ Hence, authors were able to prolong pregnancy by 51 days even after the Doppler indices showed absent end diastolic flow in both umbilical arteries and prevent prematurity, with the use of vaginal Sildenafil citrate without any side effects to the mother as well as the fetus.

\section{CONCLUSION}

Long term fetal complications are associated with severe IUGR/ FGR and prematurity. Authors were able to prevent these complications by prolonging pregnancy and thereby increasing EFW in the patient by using Sildenafil citrate $25 \mathrm{mg}$ thrice daily vaginally. Sildenafil citrate, as a vasodilator has emerged as a potential management option in the treatment of IUGR/ FGR.

\section{Funding: No funding sources \\ Conflict of interest: None declared \\ Ethical approval: Not required}

\section{REFERENCES}

1. Imdad A, Yakoob MY, Siddiqui S, Bhutta ZA. Screening and triage of intrauterine growth restriction (IUGR) in general population and highrisk pregnancies: a systematic review with a focus on reduction of IUGR related stillbirths. BMC Public Health. 2011;11(3):S1.

2. Sakamoto M, Osato K, Kubo M, Nii M, Tanaka H, Murabayashi N, et al. Early-onset fetal growth restriction treated with the long-acting phosphodiesterase-5 inhibitor tadalafil: a case report. J Med Case Rep. 2016;10(1):317.

3. Smith-Bindman R, Chu PW, Ecker JL, Feldstein VA, Filly RA, Bacchetti P. US evaluation of fetal growth: prediction of neonatal outcomes. Radiol. 2002;223(1):153-61.

4. Connelly D. Three decades of Viagra. Pharma J. 2017. Available at: https://www.pharmaceuticaljournal.com/news-and-analysis/infographics/threedecades-of-viagra/20202847.article.

5. Casanello P, Castro-Rodriguez JA, Uauy R, Krause BJ. Placental epigenetic programming in intrauterine growth restriction (IUGR). Chilean $\mathrm{J}$ Pediatr. 2016;87(3):154-61

6. Travadi JN, Patole SK. Phosphodiesterase inhibitors for persistent pulmonary hypertension of the newborn: a review. Pediatr Pulmonol. 2003;36:52955.

7. Downing JW, Ramasubramanian R, Johnson RF, Minzter BH, Paschall RL, Sundell HW, et al. Hypothesis: selective phosphodiesterase-5 inhibition 
improves outcome in preeclampsia. Med Hypotheses 2004;63:1057-64.

8. Sebire NJ, Talbert D. 'Corplacentale': placental intervillus/intravillus blood flow mismatch is the pathophysiological mechanism in severe intrauterine growth restriction due to uteroplacental disease. Med Hypotheses. 2001;57:354-7.

9. Wareing M, Myers JE, O'Hara M, Kenny LC, Taggart MJ, Skillern L, et al. Phosphodiesterase-5 inhibitors and omental and placental small artery function in normal pregnancy and pre-eclampsia. Eur J Obstet Gynecol Reprod Biol. 2006;127(1):41-9.

10. Wareing M, Myers JE, O'Hara M, Baker PN. Sildenafil citrate (Viagra) enhances vasodilatation in fetal growth restriction. J Clin Endocrinol Metab. 2005;90(5):2550-5.

11. Ballard SA, Gingell CJ, Tang K, Turner LA, Price ME, Naylor AM. Effects of sildenafil on the relaxation of human corpus cavernosum tissue in vitro and on the activities of cyclic nucleotide phosphodiesteraseisozymes. J Urol. 1998;159(6):2164-71.

12. Choudhary R, Desai K, Parekh H, Ganla K. Sildenafil citrate for the management of fetal growth restriction and oligohydramnios. Int $\mathrm{J}$ Womens Health. 2016;8:367-72.

13. von Dadelszen P, Dwinnell S, Magee LA, Carleton BC, Gruslin A, Lee B, et al. Sildenafil citrate therapy for severe early-onset intrauterine growth restriction. BJOG. 2011;118(5):624-8.

Cite this article as: Choudhary RA, Patrawala K, Desai K, Ganla K. Sildenafil citrate therapy in absent end diastolic flow in umbilical artery in an early onset fetal growth restriction (FGR) fetus. Int J Reprod Contracept Obstet Gynecol 2018;7:5173-7. 